\title{
The evaluation of factors affecting antibody response after administration of the BNT162b2 vaccine: A prospective study in Japan
}

\author{
Toshiya Mitsunaga \\ Yuhei Ohtaki ${ }^{2}$, Yutaka Sek \\ Syunsuke Mashiko ${ }^{2}$, Satoshi Takeda ${ }^{2}$, Kunihiro Mashiko \\ 1 \\ 2 \\ 2 Department of Emergency Medicine, Jikei University School of Medicine, Tokyo, Japan \\ 3 Department of Cardiology, Association of EISEIKAI Medical and Healthcare Corporation Minamitama Hospital, Tokyo, Japan \\ 4 Department of Internal Medicine, Association of EISEIKAI Medical and Healthcare Corporation Minamitama Hospital, Tokyo, Japan \\ 5 Department of Medical Engineering, Association of EISEIKAI Medical and Healthcare Corporation Minamitama Hospital, Tokyo, Japan \\ 6 Department of Pharmacy, Association of EISEIKAI Medical and Healthcare Corporation Minamitama Hospital, Tokyo, Japan \\ Corresponding Author: Toshiya Mitsunaga \\ Email address: toshiya.m@jikei.ac.jp
}

Masakata Yoshioka ${ }^{4}$, Hiroshi Mori $^{5}$, Midori Suzuka $^{6}$,

The aim of this study was to evaluate the antibody reaction after administration of the BNT162b2 vaccine, and to reveal the factors that affect antibody production. This prospective study was carried out in the Association of EISEIKAI Medical and Healthcare Corporation Minamitama Hospital, in Tokyo, Japan, from April 15, 2021 to June 09, 2021. All our hospital's workers who were administered the BNT162b2 vaccine as part of a routine program were included in this study. We calculated the anti-SARS-CoV-2 spikespecific antibody titter 1 ) before vaccination, 2) seven to twenty days after the first vaccination, and 3 ) seven to twenty days after the second vaccination. The low-antibody titer group ( $L A B G$ ) was defined as the group having less than 25 percentiles of antibody titer. Univariate and Multivariate logistic regression analysis were performed to ascertain the effects of factors on the likelihood of LABG. 374 participants were eventually included in our study, and they were divided into 94 LABG and 280 non-LABG. All samples showed significant antibody elevation in the second antibody test, with a mean value of 3476 $\mathrm{U} / \mathrm{mL}$. When comparing the LABG and non-LABG groups, the median age, blood sugar, and $\mathrm{HbAlc}$ were significantly higher in the LABG group. The rates of participants with low BMI $(<18.5)$ and high BMI (>30) were significantly higher in the LABG group. The proportion of chronic lung disease, hypertension, diabetes, dyslipidemia, autoimmune disease, and cancer were significantly higher in the LABG group. Although there was no significant difference confirmed with respect to the exercise hours per day, the proportion of participants that did not perform outdoor exercises was significantly higher in the LABG group. The time interval between the second vaccination and the second antibody test, 
and between the first and the second vaccination was significantly longer in the non-LABG group. In the multivariate logistic regression analysis, older than sixty years, the past history of hypertension, $\mathrm{HbAlc}$ higher than $6.5 \%$, and lack of outdoor exercises were significant suppressors of antibody responses, whereas the length of days from the first to the second vaccination longer than twenty-five days promoted a significant antibody response.Again, our single-center study demonstrates that older than sixty years, hypertension, $\mathrm{HbAlc}$ higher than $6.5 \%$, and lack of outdoor exercises were significant suppressors of antibody responses, whereas the length of days from the first to the second vaccination longer than twenty-five days promoted a significant antibody response.

Evidence from multi-center studies is needed to develop further vaccination strategies. 
1 The evaluation of factors affecting antibody response after

2 administration of the BNT162b2 vaccine: A prospective

3 study in Japan

4

5 Toshiya Mitsunaga ${ }^{1,2}$, Yuhei Ohtaki ${ }^{2}$, Yutaka Seki ${ }^{1,3,4}$, Masakata Yoshioka $^{4}$, Hiroshi Mori ${ }^{5}$,

6 Midori Suzuka $^{6}$, Syunsuke Mashiko ${ }^{2}$, Satoshi Takeda ${ }^{2}$, Kunihiro Mashiko ${ }^{1}$

7

$8 \quad{ }^{1}$ Department of Emergency Medicine, Association of EISEIKAI Medical and Healthcare

9 Corporation Minamitama Hospital, Tokyo, Japan

$10{ }^{2}$ Department of Emergency Medicine, Jikei University School of Medicine, Tokyo, Japan

$11{ }^{3}$ Department of Cardiology, Association of EISEIKAI Medical and Healthcare Corporation

12 Minamitama Hospital, Tokyo, Japan

$13{ }^{4}$ Department of Internal Medicine, Association of EISEIKAI Medical and Healthcare

14 Corporation Minamitama Hospital, Tokyo, Japan

$15{ }^{5}$ Department of Medical Engineering, Association of EISEIKAI Medical and Healthcare

16 Corporation Minamitama Hospital, Tokyo, Japan

$17{ }^{6}$ Department of Pharmacy, Association of EISEIKAI Medical and Healthcare Corporation

18 Minamitama Hospital, Tokyo, Japan

19

20

21

Corresponding Author:

Toshiya Mitsunaga ${ }^{1,2}$

3-10-1, Sanda-machi, Hachioji-city, Tokyo, 1930832, Japan

Email address: toshiya.m@jikei.ac.jp 


\section{Abstract}

26 The aim of this study was to evaluate the antibody reaction after administration of the

27

28

29

30

31

32

33

34

35

36

37

38

39

40

41

42

43

44

45

46

47

48

49

50

51

52

53

54

55

56

57

58

59

60

61

62

63

64

65

66

67

68

69

70 BNT162b2 vaccine, and to reveal the factors that affect antibody production. This prospective study was carried out in the Association of EISEIKAI Medical and Healthcare Corporation Minamitama Hospital, in Tokyo, Japan, from April 15, 2021 to June 09, 2021. All our hospital's workers who were administered the BNT162b2 vaccine as part of a routine program were included in this study.

We calculated the anti-SARS-CoV-2 spike-specific antibody titter 1) before vaccination, 2) seven to twenty days after the first vaccination, and 3) seven to twenty days after the second vaccination.

The low-antibody titer group (LABG) was defined as the group having less than 25 percentiles of antibody titer. Univariate and Multivariate logistic regression analysis were performed to ascertain the effects of factors on the likelihood of LABG. 374 participants were eventually included in our study, and they were divided into 94 LABG and 280 non-LABG. All samples showed significant antibody elevation in the second antibody test, with a mean value of 3476 $\mathrm{U} / \mathrm{mL}$.

When comparing the LABG and non-LABG groups, the median age, blood sugar, and HbA1c were significantly higher in the LABG group. The rates of participants with low BMI $(<18.5)$ and high BMI $(>30)$ were significantly higher in the LABG group. The proportion of chronic lung disease, hypertension, diabetes, dyslipidemia, autoimmune disease, and cancer were significantly higher in the LABG group. Although there was no significant difference confirmed with respect to the exercise hours per day, the proportion of participants that did not perform outdoor exercises was significantly higher in the LABG group. The time interval between the second vaccination and the second antibody test, and between the first and the second vaccination was significantly longer in the non-LABG group.

In the multivariate logistic regression analysis, older than sixty years, the past history of hypertension, HbA1c higher than $6.5 \%$, and lack of outdoor exercises were significant suppressors of antibody responses, whereas the length of days from the first to the second vaccination longer than twenty-five days promoted a significant antibody response. Again, our single-center study demonstrates that older than sixty years, hypertension, HbA1c higher than $6.5 \%$, and lack of outdoor exercises were significant suppressors of antibody responses, whereas the length of days from the first to the second vaccination longer than twenty-five days promoted a significant antibody response. Evidence from multi-center studies is needed to develop further vaccination strategies. 
71

72

73

74

75

76

77

78

79

80

81

82

83

84

85

86

87

88

89

90

91

92

93

94

95

96

97

98

99

100

101

102

103

104

105

106

107

108

109

110

111

112

113

114

115

116

\section{Introduction}

The severe acute respiratory syndrome coronavirus 2 (SARS-CoV-2), which was first detected in Wuhan, China, has spread all over the world significantly faster. By the end of April 2021, the number of cases infected with SARS-CoV-2 had exceeded 150 million, with more than 3.1 million deaths (mortality rate: 2.1\%) (World Health Organization, 2021). According to the Ministry of Health, Labour and Welfare of Japan, the number of coronavirus 2019 (Covid-19) cases confirmed by 30 April 2021 in Japan was 588,900, with 10,226 deaths (mortality rate: 1.74\%) (The Ministry of Health, Labour and Welfare, 2021.). Many developed countries in cooperation with the World Health Organization (WHO) have been trying to reduce the number of Covid-19 cases. However, because of its strong infectivity, it has been very challenging to control this disease.

The majority of patients infected with Covid-19 were mild cases, but approximately 5\% of cases progressed to severe conditions, and approximately $2 \%$ died (Li et al., 2020.). Several studies have suggested that the risk factors for severe Covid-19 involve individual's age, gender (males are at higher risk compared to females), smoking, and pre-existing conditions such as obesity, diabetes, chronic lung disease, hypertension, dyslipidemia, and chronic kidney disease (Matsunaga et al., 2020; Mi et al., 2020; Liang et al., 2020; Lippi et al., 2020; Myers et al., 2020; Fadini et al., 2020; Zheng et al., 2020; Popkin et al., 2020). Although several treatment strategies, including steroids and antiviral drugs, have been developed, vaccination is still the most important means of preventing Covid-19 infection and aggravation in people with these risk factors. BNT162b2 is a new generation vaccine with nucleoside-modified RNA molecules encoding the full-length SARS-CoV-2 spike glycoprotein (Polack et al., 2020). A previous study showed that the efficacy of this vaccine in preventing Covid-19 is approximately $95 \%$, and thus extremely high (Polack et al., 2020). Typically, people have to be vaccinated twice to boost their immunity, and the study carried by Walsh et al showed that spike binding IgG titer increased dramatically and reached a plateau after only seven days from the second dose (Walsh et al., 2020). However, the major studies of Covid-19 vaccines are carried out in non-Asian countries, and the true efficacy of this vaccine in Asian people is still unclear (Polack et al., 2020; Walsh et al., 2020).

Certain studies have been identifying the factors that promote or suppress antibody response post vaccination include obesity, age, sleep duration etc. A study performed by Pellini et al showed that age and gender, which were the risk factors for severe Covid-19, may also be interfering factors for SARS-CoV-2 vaccine immunogenicity (Pellini et al., 2021). However, the population of this study was relatively small and only included non-Asian populations. In contrast, the studies performed by Tanja et al and Prather et al demonstrated that sleep duration and sleep quality, which reflect the circadian rhythm, were positively correlated to antibody production after Influenza vaccination or Hepatitis A vaccination, respectively (Tanja et al., 2003; Prather et al., 2021). However, to our knowledge, there have been no studies that evaluate the relationship between the factors involved in the daily life rhythm and the antibody response after Covid-19 vaccination.

Therefore, the aim of this study was to evaluate the anti-SARS-CoV-2 spike-specific antibody reaction following the administration of BNT162b2 vaccine, and to reveal the factors that affect antibody response in a Japanese population.

\section{Materials \& Methods Study design}


117 This prospective study was carried out between April 15, 2021 and June 9, 2021 at the

118 Association of EISEIKAI Medical and Healthcare Corporation Minamitama Hospital, a

119 secondary emergency medical institution. The protocol for this research project was approved by

120 a suitably constituted Ethics Committee of the institution and conforms to the provision of the

121 Declaration of Helsinki (Committee of Association of EISEIKAI Medical and Healthcare

122 Corporation Minamitama Hospital, Approval No. 2020-Ack-19), and written consent was

123 obtained from all the human subjects.

124 Study setting and population

125 All our hospital's workers, who were administered with the BNT162b2 vaccine (COMIRNATY ${ }^{\circledR}$

126 (Tozinameran)) as part of a routine program, were included in this study. The exclusion criteria

127 were as follows: 1) cases that we could not obtained informed consent, 2) cases with past Covid-

12819 infection, 3) cases whose antibody titer before vaccination was elevated, 4) cases with new

129 Covid-19 infection after vaccination, and 5) cases who could not provide a blood sample within

130 the expected deadline (i.e., twenty days post-vaccination).

131 Data sources and measurements

132 A 5-ml blood sample was drawn from the intermediate cubital vein, and we determined the anti-

133 SARS-CoV-2 antibody titer (Elecsys ${ }^{\circledR}$ Anti-SARS-CoV-2 S RUO, Roche Diagnostics K.K.) a)

134 before vaccination (baseline), b) seven to twenty days after the first vaccination (first antibody

135 test), and c) seven to twenty days after the second vaccination (second antibody test). We

136 performed biochemical examinations (AST: aspartate aminotransferase, ALT: alanine

137

138

139

140

141

142

aminotransferase, $\gamma$-GT: $\gamma$-glutamyl transpeptidase, Alb: albumin, TG: triglyceride, HDL-C: high density lipoprotein cholesterol, LDL-C: low density lipoprotein cholesterol, Cr: Creatinine, BS: Blood Sugar, HbA1c: Hemoglobin A1c, CRP: C - reactive protein) and we also calculated the blood cell count (White Blood Cells, Hemoglobin, Hematocrit, and Platelets) before vaccination. Self-reports were used to register participants' information with respect to their age, gender, past medical histories (1. Chronic lung disease (Chronic obstructive pulmonary disease: COPD), 2.

143

144 Chronic lung disease (non-COPD), 3. Cardiac disease, 4. Hypertension, 5. Diabetes, 6. Dyslipidemia, 7. Liver disease (hepatitis, cirrhosis, and any liver disorder), 8. Chronic kidney disease: CKD, 9. Autoimmune disease, 10. Cancer), medication (1. Antihypertensive drug, 2. Antidiabetic drug, 3. Antilipid drug, 4. Antiplatelet and Anticoagulant drug, 5. Immunosuppressive drug, 6. Immunoglobulin preparations), smoking habits (current smoking history: smoking more than once a week within a year, past smoking history: smoking more than once a week over a year ago), habits of drinking alcohol (drinking more than once a week), sleep duration per day, the quality of sleep (good or disturbed), exercise (both of indoor and outdoor exercises) hours per day, the number of outdoor exercises (all outdoor exercises such as camping, mountaineering, scuba diving, skiing, or ball games etc.) days per week, and the length of days for vaccination and antibody test. Body mass index (BMI) was calculated based on the height and body weight which were actually measured before vaccination.

The diagnostic definition of the above diseases conformed to the WHO guideline, and we defined obesity as follows: 1) Underweight: $\mathrm{BMI}<18.5,2)$ Normal range: $18.5 \leqq \mathrm{BMI}<25,3$ ) Pre-obese: $25 \leqq \mathrm{BMI}<30,4)$ Obese class I: $30 \leqq \mathrm{BMI}<35,5)$ Obese class II: $35 \leqq \mathrm{BMI}<40$, 6) Obese class III: $40 \leqq$ BMI (World Health Organization, 2020). of antibody titer, whereas non-LABG was defined as having more than 25 percentiles of antibody titer. 


\section{Statistical analysis}

164 A sample size of 460 participants was determined based upon 70\% power, 0.05 significance 165 level, 0.3 effect size, three allocation ration, and $20 \%$ attrition. Unadjusted analysis evaluated

166

167 between low and non-low-antibody titer group using the Student's $t$ test and Mann-Whitney $U$ test for continuous variables, which were described as medians and interquartile ranges (IQR), and Fisher's exact test or Pearson's $\chi^{2}$ test for categorical variables, which were described as numbers and percentages. Univariate and Multivariate logistic regression analysis was performed to ascertain the effects of factors on the likelihood of LABG. Odds ratios and corresponding 95\% confidence intervals were calculated. A $p$ value of less than 0.05 was considered to indicate statistical significance. Data were analyzed with the Statistical Package for the Social Sciences, version 26.0 (SPSS, Chicago, IL, USA).

\section{Results}

Of the 501 participants who fulfilled the inclusion criteria of this study, we excluded 96 participants because we did not obtain consents, seven participants because of past Covid-19 infection, one participant because of antibody titer elevation prior to the vaccination, one participant because of suspected new Covid-19 infection after first vaccination with unexplained abnormal antibody elevation, and 22 participants because they could not provide a blood sample within the respective deadline. Finally, 374 participants were analyzed that were divided into 94 LABG and 280 non-LABG (Fig 1). In addition, we were unable to obtain the information on adverse reactions in 15 of 374 participants.

The baseline characteristics are shown in Table 1. The median age (interquartile range) of the participants was 36 (16.0) years, and $110(29.4 \%)$ participants were males. Furthermore, 53 (14.2\%) participants with pre-obesity (BMI: 25-30) and 19 (5.0\%) participants with obesity (BMI: $>30$ ) and zero participants belonging in the obese class III were identified. With respect to comorbidities, $118(31.6 \%)$ participants had past medical histories, chronic lung disease (35 cases: $9.4 \%$ ), hypertension (30 cases: $8.0 \%$ ), and dyslipidemia (16 cases: $4.3 \%)$. The number of systemic adverse reactions of second vaccination was higher than that of first vaccination. The median duration (interquartile range) between the time from the first vaccination to the first antibody test, and from the second vaccination to the second antibody test was eight (1) days. Moreover, the median length of days from the first to the second vaccination was 22 (3) days. Almost all antibody titer was not elevated in the first antibody test, and only $23(6.2 \%)$ samples exhibited a slight positive antibody response, with a mean value of $0.41 \mathrm{U} / \mathrm{mL}$. All samples showed significant antibody elevation in the second antibody test, with a mean value of 3476 $\mathrm{U} / \mathrm{mL}$ (Fig 2).

Figure 3 shows the distribution of log antibody titers post second vaccination by relevant age groups. By the age of 50s, the median of the log antibody titers decreases slowly and significantly. In the group over 60 years, a further decrease in the log antibody titer was observed.

Table 2 shows the comparison between LABG and non-LABG. The median age and HbA1c were significantly higher in the LABG group $(\mathrm{p}<0.001,<0.01)$. The proportion of males $(62$ $(33.2 \%)$ vs females $(48(25.7 \%))$ was greater in the LABG group, but with no significant differences $(\mathrm{p}=0.38)$. Moreover, the proportion of participants with low BMI $(<18.5)$ and high BMI $(>30)$ were significantly higher in the LABG group $(\mathrm{p}<0.05)$. The proportion of chronic lung disease, hypertension, diabetes, dyslipidemia, autoimmune disease, and cancer was significantly higher in the LABG group $(p<0.05)$. There was no significant difference in the 
209 proportion of adverse reactions between the two groups. Although no significant difference was

210 confirmed in the hours of exercise per day, the proportion of participants with no-outdoor

211 exercises was significantly higher in the LABG group $(\mathrm{p}<0.001)$. Finally, the length of days

212 from the second vaccination to the second antibody test, and from the first to the second

213 vaccination was significantly longer in the non-LABG group $(\mathrm{p}<0.05,<0.05)$.

214 Table 3 shows the univariate and multivariate logistic regression analysis of the factors

215 associated with LABG. In the univariate logistic regression analysis, older than sixty years, the

216 past history of hypertension, HbAlc higher than $6.5 \%$, and lack of outdoor exercises were a

217 significant suppressor of the antibody response, and their odds ratios were 4.70, 3.35, 14.72, and

218 2.29. On the other hand, the length of days from the first to the second vaccination longer than

219 twenty-five days promoted a significant antibody response, and the odds ratio was 0.49 . In

220 addition, the multivariate logistic regression analysis, showed that older than sixty years, HbAlc

221 higher than $6.5 \%$ and lack of outdoor exercises were significant suppressors of the antibody

222 response, and their odds ratios were 4.99, 2.58, 10.99, and 2.39. On the other hand, the length of

223 days from the first to the second vaccination longer than twenty-five days was promoted a

224 significant antibody reaction, and the odds ratio was 0.47 .

225

226

227

228

229

230

231

232

233

234

235

236

237

238

239

240

241

242

243

244

245

246

247

248

249

250

251

252

\section{Discussion}

Our data showed that the antibody titer was dramatically elevated after the second administration of the BNT162b2 vaccine at thirty micrograms in Japanese people. Moreover, our study identified that older age, past hypertension history, HbAlc more than $6.5 \%$, and performing nooutdoor exercises were significant suppressors of antibody response, as opposed to the duration between the first and the second vaccination longer than twenty-five days which were found to promote a significant antibody response. This is the first study that evaluated the antibody response in a relatively large cohort following mRNA vaccination for SARS-CoV-2 in Japan, and assessed various factors in terms of promoting or suppressing a subsequent antibody response.

According to previous studies, the mean S1-Binding IgG titers at twenty-one days postadministration of first vaccination at thirty micrograms was $1,265 \mathrm{U} / \mathrm{ml}$ in participants eighteen to fifty-five years of age, and that in participants sixty-five to eighty-five years of age was lower at $329 \mathrm{U} / \mathrm{ml}$. Furthermore, the mean S1-Binding IgG titers at seven days post-administration of second vaccination at 30 micrograms dramatically elevated at $9,136 \mathrm{U} / \mathrm{ml}$ in participants eighteen to fifty-five years of age, and that in participants sixty-five to eighty-five years of age was slightly lower at 7,985 U/ml (Walsh et al., 2020). In the present study, participants demonstrated that positive anti-SARS-CoV-2 spike-specific antibody reactions rate dramatically increased from $6.2 \%$ in the first antibody test to $100 \%$ in the second antibody test. The mean anti-SARS-CoV-2 spike-specific antibody titers were $0.2 \mathrm{U} / \mathrm{mL}$ in the first antibody test and $3,476 \mathrm{U} / \mathrm{mL}$ in the second antibody test, and our findings demonstrate that the second dose of the BNT162b2 two-dose vaccine can also efficiently enhance the immunity of Asian people. Several studies and guidelines showed that older age (more than 65 years), male, obesity, diabetes, chronic lung disease, hypertension, dyslipidemia, chronic kidney disease and smoking were risk factors for the development of severe Covid-19 (Matsunaga et al., 2020; Mi et al., 2020; Liang et al., 2020; Lippi et al., 2020; Myers et al., 2020; Fadini et al., 2020; Zheng et al., 2020; Popkin BM et al., 2020). 
253 A study performed by Pellini et al demonstrated that age and male sex may be hampering SARS254 CoV-2 vaccine immunogenicity (Pellini et al., 2021), but the sample size was not large so that 255 the evidence is limited.

256 Obesity, which also causes diabetes and hypertension, is one of the most important risk factors of 257 severe Covid-19 by suppressing immune system responses. In this study, we defined obesity in 258 accordance with the WHO guidelines (World Health Organization, 2020). A common definition 259 of obesity is important for comparing results of studies performed in different countries, 260 especially when it comes to the identification of immune responses pertaining to racial 261 differences. A previous review by Millner et al showed that the excess adipose tissue could block 262 Vandanmagsar et al revealed that low levels of inflammation and relatively high levels of inflammatory cytokines induced by adipose tissue can decrease immune responses, and especially T lymphocyte activity (Vandanmagsar et al., 2011). These immune cell suppression mechanisms can reduce the subsequent antibody production. In the present study, obese participants with a BMI over thirty had higher odds ratio for lowantibody response, but was not significant. As we mentioned in the limitation, the reason why there was no significant difference may be related to the decrease in detectability due to the small number of obese people with a BMI of thirty or higher. Similar to obesity, diabetes is also a significant risk factor element for the development of severe Covid-19, and a report by Fadini et al showed that the presence of diabetes increases the risk by 2.3 times (Fadini et al., 2020). In addition, Berbudi et al showed that hyperglycemia could inhibit IL-6 production, which induces antibodies and T cells (Berbudi et al., 2020), and that this was a mechanism that triggered low-antibody production. Our study showed that the median $\mathrm{HbAlc}$ were significantly higher in the LABG group, furthermore, it was the largest factor that suppressed antibody reaction in multivariate regression analysis.

Gustafson et al exhibited that the immune response toward vaccination is controlled by a delicate balance of effector $\mathrm{T}$ cells and follicular $\mathrm{T}$ cells, yet the aging process disturbs this balance. Several changes in $T$ cells have been identified that contribute to age-related defects of posttranscriptional regulation, T cell receptor signaling, and metabolic function (Gustafson et al., 2020). Similar to Pellini's study, our study revealed that the antibody titer after mRNA SARS$\mathrm{CoV}-2$ vaccine significantly reduces in particularly participants over sixty years.

The Japanese Covid-19 guideline does not include gender in the risk factors for severe Covid-19, but a report published overseas indicated that male patients are approximately three times more likely to be admitted to intensive care units and have a higher mortality rate (Mi et al., 2020). Females are known to be sensitive to immune responses, including antibody production to infectious diseases, which in turn induces the development of autoimmune diseases (Fischinger et al., 2019).

Differences in sex hormones are associated with gender differences in vaccine-induced immunity. For example, testosterone levels and Influenza vaccine antibody titer have been shown to be inversely correlated (Markle et al., 2014; Ruggieri et al., 2016; Furman et al., 2014). Genetic differences, as well as sex hormone differences, affect vaccine-induced immunity. The $\mathrm{X}$ chromosome expresses 10 times more genes than the $\mathrm{Y}$ chromosome, and differences in gene expression between the $\mathrm{X}$ and $\mathrm{Y}$ chromosomes promote differences in vaccine-induced immunity by gender (Fischinger $S$ et al., 2019). Our study showed that although not significant the proportion of males was larger in the LABG group, a finding that agrees with current literature. 
299 Furthermore, and although there was no difference in the exercise hours between the two groups, 300 including indoor activities, our study revealed that the proportion of no-outdoor exercises days 301 was significantly larger in the LABG group. Moreover, participants that did not perform outdoor 302 exercises had a significantly higher odds ratio, which was 2.39 in multivariate analysis.

303 Although there are several differences between exercises, including indoor activities, and 304 outdoor exercises, we focused on exposure to sunlight and the associated vitamin D.

305 Researchers have long focused on the effect of vitamin D on the activation of the immune 306 system, and a study carried by Kashi et al showed that there was a positive correlation between 307 plasma vitamin D levels and post-vaccination antibody titer for Hepatitis B (Kashi et al., 2021). 308 Although no studies have further clarified the relationship between antibody titer and vitamin D 309 levels after vaccination for Covid-19, Merzon et al found that low plasma vitamin D levels or 310 short duration of exposure to sunlight were associated with an increased risk of Covid-19 311 infection (Merzon et al., 2020). Therefore, although vitamin D levels could not be measured in 312 this study, vitamin D levels may be positively correlated with immune responses following 313 administration of the BNT162b2 vaccine.

314 Parry et al. showed that the antibody response was 3.5-fold higher in cases of delayed second 315 vaccination dose (12 weeks after he first vaccination), and the cellular immune responses were 316 3.6-fold lower compared to cases with normal vaccination schedule (Parry et al., 2021). Our 317 study revealed that a longer interval between the first and the second vaccination had a 318 significant positive correlation with antibody response.

319 The antibody titer level does not necessarily reflect the immune function against pathogens.

320

321

322

323

324

325

326

327

328

329

330

331

332

333

334

335

336

337

338

339

340

341

342

343

344 However, our study showed that lifestyle improvements such as performing outdoor exercises and reducing complications such as obesity may increase the immune response of the BNT162b2 vaccine, and this fact is especially important for people with risk factors for severe Covid-19. In addition to this, further research of the vaccination schedule is also needed for promoting immune responses after BNT162b2 vaccine administration, especially to older people. Our study has several limitations. First, we only diagnosed new Covid-19 infections to participants through symptoms of fever and common cold. Therefore, we were unable to identify asymptomatic infections. However, our data showed that the number of antibody-positive cases at baseline, without any previous episode of Covid-19 infection was only one $(0.3 \%)$, and thus had low statistical power. Second, we only calculated the antibody titer but not the T-cell responses. Consequently, we could not evaluate the effect of these factors to the entire immune system. Third, we calculated the anti-SARS-CoV-2 spike-specific antibody reactions but not the neutralization antibody titer, so that the anti-pathogenic activity has not been evaluated. Forth, the information may not be accurate as we have collected patient information by self-reports. Finally, we only included relatively healthy medical workers, but did not include participants with severe complications, and this may have reduced the difference between the LABG and non-LABG groups. Further large-scale studies that include participants with several concurrent conditions are needed in the future.

\section{Conclusions}

Our single-center study demonstrated that older than sixty years, the past history of hypertension, $\mathrm{HbAlc}$ higher than $6.5 \%$, and lack of outdoor exercises were significant suppressors of antibody responses, whereas the length of days from the first to the second vaccination longer than twenty-five days promoted a significant antibody response. Evidence from multi-center studies is needed to develop further vaccination strategies. 


\section{References}

World Health Organization. 2021. WHO Coronavirus (COVID-19) Dashboard. Available from: https://covid19.who.int

The Ministry of Health, Labour and Welfare, Japan. 2021. Coronavirus disease 2019 (COVID19) situation within and outside the country. Available from: http://www.mhlw.go.jp/stf/seisakunitsuite/bunya/newpage_00032.html

Li LQ, Huang Tian, Wang YQ, Wang ZP, Liang Y, Huang TB, Zhang HY, Sun W, Wang Y. 2020. COVID-19 patient's clinical characteristics, discharge rate, and fatality rate of metaanalysis. Journal of Medical Virology 92(6): 577-583.

Matsunaga N, Hayakawa K, Terada M, Ohtsu H, Asai Y, Tsuzuki S, Suzuki S, Toyoda A, Suzuki K, Endo M, Fujii N, Suzuki M, Saito S, Uemura Y, Shibata T, Kondo M, Izumi K, Terada-Hirashima J, Mikami A, Sugiura W, Ohmagari N. 2020. Clinical epidemiology of hospitalized patients with COVID-19 in Japan: Report of the COVID-19 REGISTRY JAPAN. Clinical Infectious Diseases. Available from: https://doi.org/10.1093/cid/ciaa1470

Mi J, Zhong W, Huang C, Zhang W, Tan L, Ding L. 2020. Gender, age and comorbidities as the main prognostic factors in patients with COVID-19 pneumonia. American Journal of Translational Research 12(10): 6537-6548.

Liang W, Guan W, Chen R, Wang W, Li J, Xu K, Li C, Ai Q, Lu W, Liang H, Li S, He J. 2020. Cancer patients in SARS-CoV-2 infection: a nationwide analysis in China. The LANCET Oncology 21(3): 335-337.

Lippi G, Henry BM. 2020. Chronic obstructive pulmonary disease is associated with severe coronavirus disease 2019 (COVID-19). Respiratory Medicine 167: 105941.

Myers LC, Parodi SM, Escobar GJ, Liu VX. 2020. Characteristics of Hospitalized Adults With COVID-19 in an Integrated Health Care System in California. JAMA 323(21): 2195-2198.

Fadini GP, Morieri ML, Longato E, Avogaro A. 2020. Prevalence and impact of diabetes among people infected with SARS-Cov-2. Journal of Endocrinological Investigation 43(6): 867-869.

Zheng Z, Peng F, Xu B, Zhao J, Liu H, Peng J, Li Q, Jiang C, Zhou Y, Liu S, Ye C, Zhang P, Xing Y, Guo H, Tang W. 2020. Risk factors of critical \& moral COVID-19 cases: A systematic literature review and meta-analysis. Journal of Infection 81(2): e16-e25.

Popkin BM, Du S, Green WD, Beck MA, Algaith T, Herbst CH, Alsukait RF, Alluhidan M, Alazemi N, Shekar M. 2020. Individuals with obesity and COVID-19: A global perspective on the epidemiology and biological relationships. Obesity Reviews 21(11): e13128.

Polack FP, Thomas SJ, Kitchin N, Absalon J, Gurtman A, Lockhart S, Perez JL, Marc GP, Moreira ED, Zerbini C, Bailey R, Swanson KA, Roychoudhury S, Koury K, Li P, Kalina WV, Cooper D, Frenck RW, Hammitt LL, Türeci Ö, Nell H, Schaefer A, Ünal S, Tresnan DB, Mather S, Dormitzer PR, Şahin U, Jansen KU, Gruber WC. 2020. Safety and Efficacy of the BNT162b2 mRNA Covid-19 Vaccine. New England Journal of Medicine 383: 2603-2615.

Walsh EE, Frenck RW, Falsey AR, Kitchin N, Absalon J, Gurtman A, Lockhart S, Neuzil K, Mulligan MJ, Bailey R, Swanson KA, Li P, Koury K, Kalina W, Cooper D, FontesGarfias C, Shi PY, Türeci Ö, Tompkins KR, Lyke KE, Raabe V, Dormitzer PR, Jansen KU, Şahin U, Gruber WC. 2020. Safety and Immunogenicity of Two RNA-Based Covid-19 
Vaccine Candidate. New England Journal of Medicine 383: 2439-50.

Pellini R, Venuti A, Pimpinelli F, Abril E, Blandino G, Campo F, Conti L, Virgilio AD, Marco FD, Domenico EGD, Bella OD, Martino SD, Ansoli F, Giannarelli D, Mandoj C, Manciocco V, Marchesi P, Mazzola F, Morretto S, Petruzzi G, Petrone F, Pichi B, Pontone M, Zocchi J, Vidiri A, Vujovic B, Piaggio G, Morrone A, Ciliberto G. 2021. Initial observations on age, gender, BMI and hypertension in antibody responses to SARS-CoV-2 BNT162b2 vaccine. EClinicalMedicine 36:100928.

Tanja L, Boris P, Horst FL, Jan B. 2003. Sleep Enhances the Human Antibody Response to Hepatitis A Vaccination. Psychosomatic Medicine 65(5): 831-835.

Prather AA, Pressman SD, Miller GE, Cohen S. 2021. Temporal Links Between Self-Reported Sleep and Antibody Responses to the Influenza Vaccine. International Journal of Behavioral Medicine 28: 151-158.

World Health Organization. 2020. Obesity and overweight. Available from: https://www.who.int/news-room/fact-she.

Milner JJ, Beck MA. 2012. Micronutrients, immunology and inflammation. The impact of obesity on the immune response to infection. Proceedings of the Nutrition Society 71: 298306.

Vandanmagsar B, Youm YH, Ravussin A, Galgani JE, Stadler K, Mynatt RL, Rayussin E, Stephens JM, Dixit VD. 2011. The NLRP3 inflammasome instigates obesity-induced inflammation and insulin resistance. Nature Medicine 17(2):179-188.

Fadini GP, Morieri ML, Longato E, Avogaro A. 2020. Prevalence and impact of diabetes amaong people infected with SARS-CoV-2. Journal of Endocrinological Investigation 43(6): 867-869.

Berbudi A, Rahmadika N, Tjahjadi AI, Ruslami R. 2020. Type 2 Diabetes and its Impact on the Immune System. Current Diabetes Review 16(5): 442-449.

Gustafson CE, Kim C, Weyand CM, Goronzy JJ. 2020. Influence of immune aging on vaccine responses. Journal of Allergy and Clinical Immunology 145(5): 1309-1321.

Fischinger S, Boudreau CM, Butler AL, Streeck H, Alter G. 2019. Sex differences in vaccineinduced humoral immunity. Seminars in immunopathology 41: 239-249.

Markle JG, Fish EN. SeXX matters in immunity. 2014. Trends in Immunology 35: 97-104.

Ruggieri A, Anticoli S, D' Ambrosio A, Giordani L, Viora M. 2016. The influence of sex and gender on immunity, infection and vaccination. Annali Ist Super Sanita 52: 198-204.

Furman D, Hejblum BP, Simon N, Jojic V, Dekker CL, Thiébaut R, Tibshirani RJ, Davis MM. 2014. Systems analysis of sex differences reveals an immunosuppressive role for testosterone in the response to influenza vaccination. Proceedings of the Natinonal Academy of Sciences of the United States of America 111(2): 869-874.

Kashi DS, Oliver SJ, Wentz LM, Roberts R, Carswell AT, Tang JCY, Jackson S, Izard RM, Allan D, Rhodes LE, Fraser WD, Greeves JP, Walsh NP. 2021. Vitamin D and the hepatitis $B$ vaccine response: a retrospective cohort study and a randomized, placebo-controlled oral vitamin D3 and simulated sunlight supplementation trial in healthy adults. European Journal of Nutrition 60: 475-491.

Merzon E, Tworowski D, Gorohovski A, Vinker S, Cohen AG, Green I, FrenkelMorgenstern M. 2020. Low plasma 25(OH) vitamin D level is associated with increased risk of COVID-19 infection: an Israeli population-based study. The FEBS Journal 287(17): 36933702.

Parry H, Bruton R, Stephens C, Brown K, Amirthalingam G, Hallis B, Otter A, Zuo J, Moss 
437 P. 2021. Extended interval BNT162b2 vaccination enhanced peak antibody generation in older 438 people. medRxiv. Doi: https://doi.org/10.1101/2021.05.15.21257017.

439 
Figure 1

Fig.1. Flowchart for sample selection.

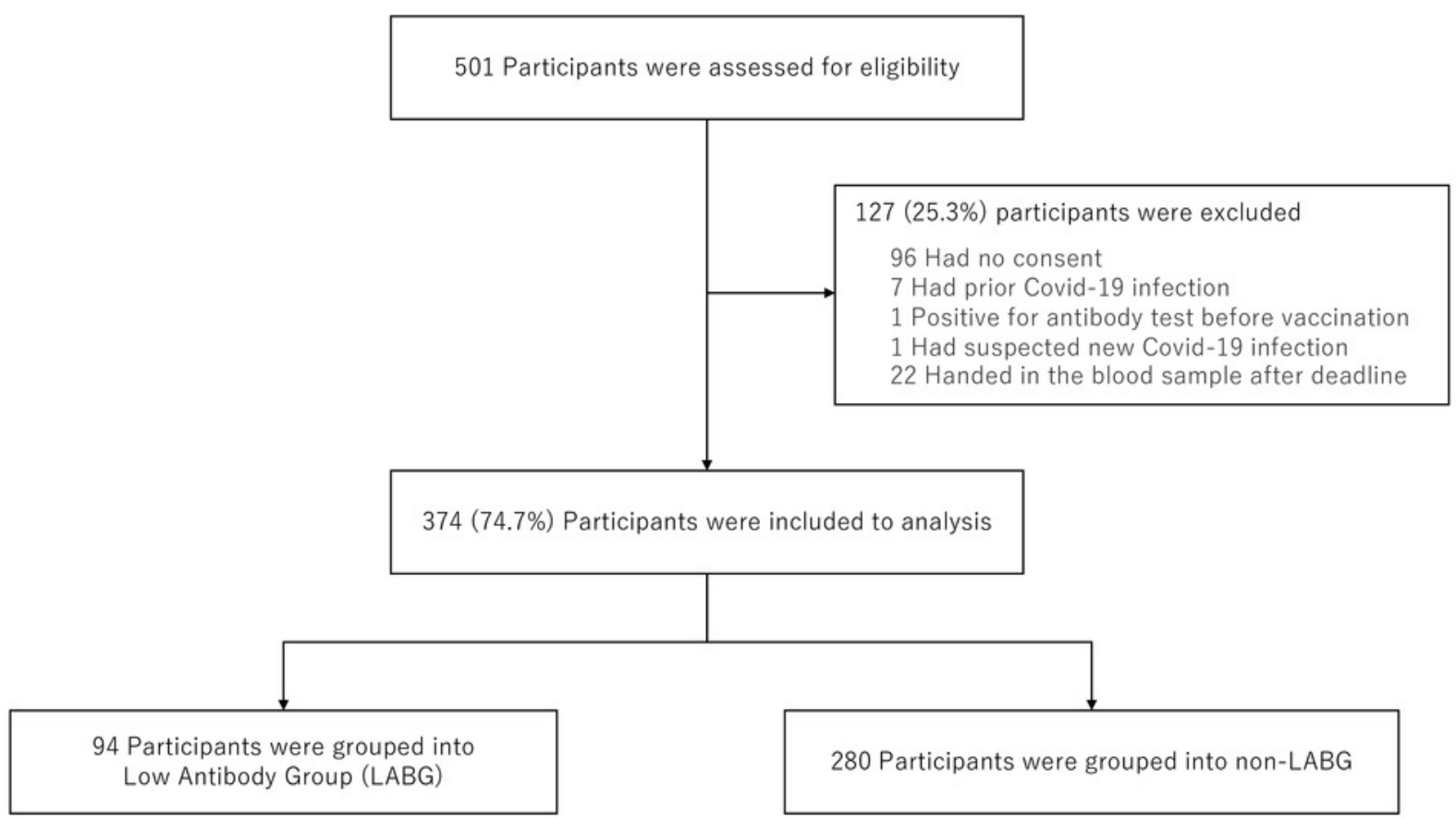




\section{Figure 2}

Fig.2. Anti-SARS-CoV-2 spike-specific antibody response to BNT162b2 vaccination.

374 participants were administered the BNT162b2 vaccine. Serum samples were obtained before injection and 7 to 20 days after the first and second vaccination. Each bar shows the geometric mean concentrations of anti-SARS-CoV-2 spike-specific antibody (lower limit of quantitation, 0.40; dashed line). The top of the vertical bar represents the mean with a $95 \%$ confidence interval (I bar). For values below the lower limit of quantification (LLOQ) $=0.40$, LLOQ/2 were included in the calculation.

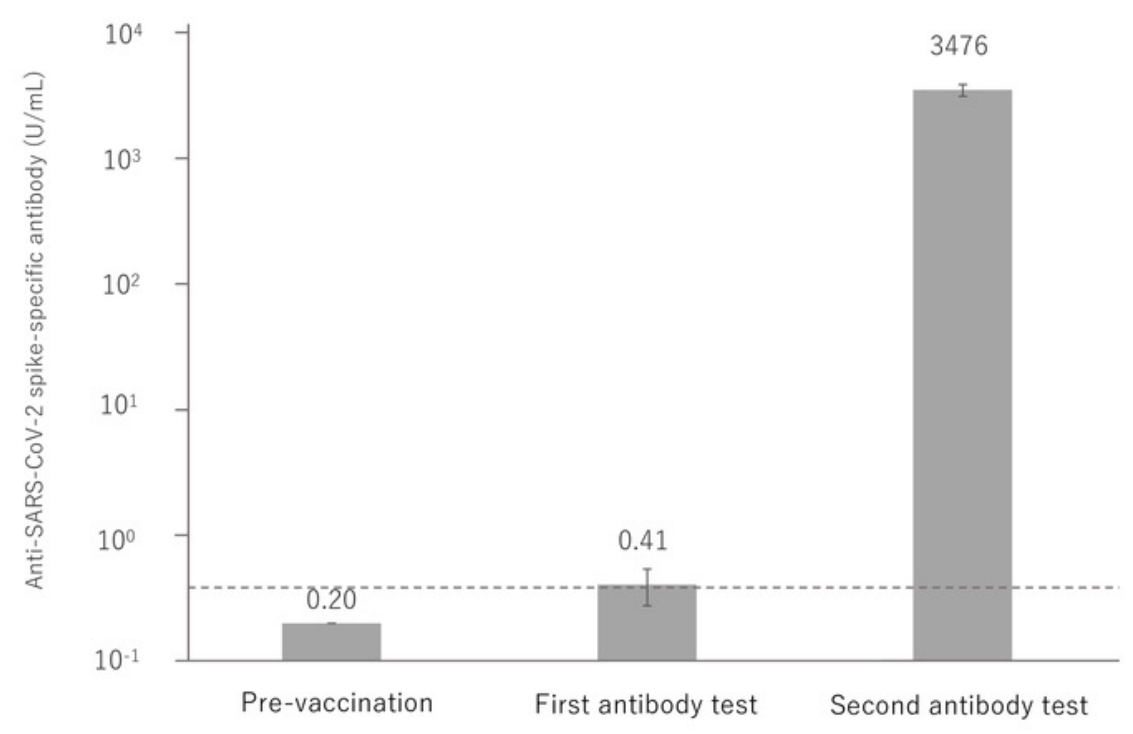


Figure 3

Fig.3. The distribution of antibody titers post second administration of BNT162b2 vaccine by relevant age groups.

$p<0.05: 20-29 y$ vs $50-59 y, 30-39 y$ vs $40-49 y$.

$p<0.01: 20-29 y$ vs $40-49 y, 20-29 y$ vs $60-69 y, 20-29 y$ vs $70-79 y, 30-39 y$ vs $60-69 y, 30-39 y$ vs $70-79 y$, $40-49 y$ vs $60-69 y, 40-49 y$ vs $70-79 y, 50-59 y$ vs $60-69 y, 50-59 y$ vs $70-79 y$.

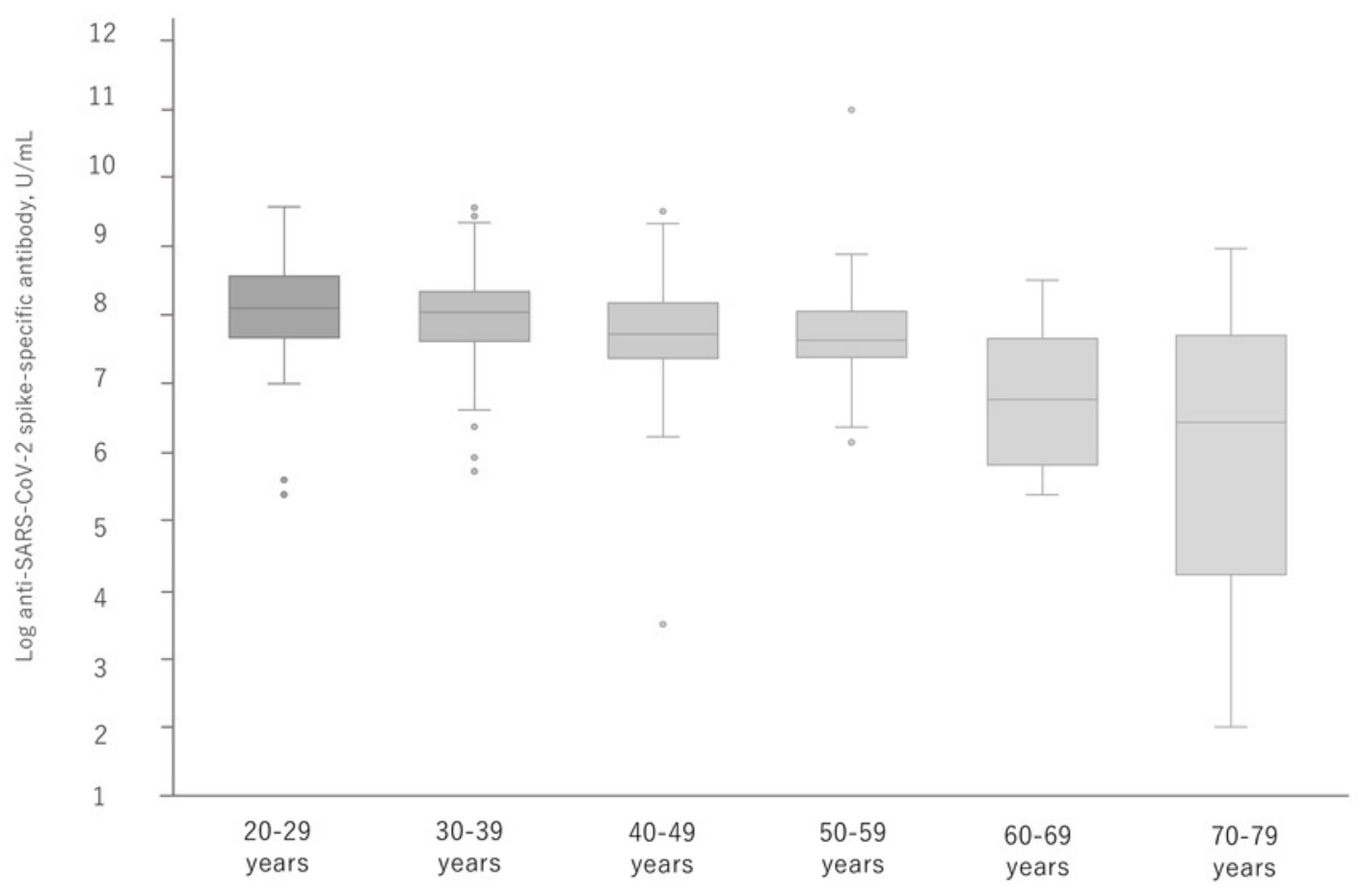




\section{Table $\mathbf{1}$ (on next page)}

Table 1. Baseline characteristics of the study population.

Data are presented as the median (interquartile range) for continuous variables and the number (\%) for categorical variables. COPD, Chronic obstractive pulmonary disease; WBC, White blood cells; Hb, Hemoglobin; Hct, Hematocrit; PLT, Platelets; Alb, Albumin; AST, Asparate aminotransferase; ALT, alanine aminotransferase; $\gamma$-GT, $\gamma$-glutamyl transpeptidase; $\mathrm{Cr}$, Creatinine; CRP, C-reactive protein; BS, Blood sugar; HbAlc, Hemoglobin Alc; HDL-C, High density lipoprotein cholesterol; LDL-C, Low density lipoprotein cholesterol; TG, Triglyceride. 


\begin{tabular}{|c|c|}
\hline & $\begin{array}{c}\text { Total Population }(\mathrm{n}=374) \\
\text { Median (interquartile range) }\end{array}$ \\
\hline Age, years & $36(16.0)$ \\
\hline \multicolumn{2}{|l|}{$\operatorname{Sex}[\mathrm{n}(\%)]$} \\
\hline Male & $110(29.4)$ \\
\hline Female & $264(70.6)$ \\
\hline \multicolumn{2}{|l|}{ Body Mass Index (BMI), kg/m2 } \\
\hline $\mathrm{BMI}<18.5$ & $34(9.1)$ \\
\hline $18.5 \leqq \mathrm{BMI}<25$ & $268(71.7)$ \\
\hline $25 \leqq \mathrm{BMI}<30$ & $53(14.2)$ \\
\hline $30 \leqq \mathrm{BMI}<35$ & $14(3.7)$ \\
\hline $35 \leqq \mathrm{BMI}<40$ & $5(1.3)$ \\
\hline \multicolumn{2}{|l|}{ Past Medical Histories [n (\%)] } \\
\hline Chronic lung disease (COPD) & $1(0.3)$ \\
\hline Chronic lung disease (non-COPD) & $34(9.1)$ \\
\hline Cardiac disease & $6(1.6)$ \\
\hline Hypertension & $30(8.0)$ \\
\hline Diabetes & $6(1.6)$ \\
\hline Dyslipidemia & $16(4.3)$ \\
\hline Liver disease & $6(1.6)$ \\
\hline Chronic kidney disease & $4(1.1)$ \\
\hline Autoimmune disease & $7(1.9)$ \\
\hline Cancer & $8(2.1)$ \\
\hline \multicolumn{2}{|l|}{ Medication $[\mathrm{n}(\%)]$} \\
\hline Antihypertensive drug & $28(7.5)$ \\
\hline Antidiabetic drug & $5(1.3)$ \\
\hline Antilipid drug & $13(3.5)$ \\
\hline Anticoagulant / Antiplatelet drug & $2(0.5)$ \\
\hline Immunosuppresive drug & $3(0.8)$ \\
\hline Immunoglobulin preparations & $4(1.1)$ \\
\hline Current smoking [n (\%)] & $70(18.7)$ \\
\hline
\end{tabular}




\begin{tabular}{|c|c|c|}
\hline \multicolumn{2}{|c|}{ Past smoking [n (\%)] } & $64(17.1)$ \\
\hline \multicolumn{2}{|c|}{ Drinking Alcohol [n (\%)] } & $229(61.2)$ \\
\hline \multicolumn{3}{|c|}{ Laboratory test } \\
\hline WBC & {$\left[\times 10^{3} / \mu \mathrm{L}\right]$} & $6.35(2.0)$ \\
\hline $\mathrm{Hb}$ & {$[\mathrm{g} / \mathrm{dL}]$} & $13.9(1.7)$ \\
\hline Hct & {$[\%]$} & $40.2(4.5)$ \\
\hline PLT & {$\left[\times 10^{4} / \mu \mathrm{L}\right]$} & $25.2(7.3)$ \\
\hline Alb & {$[\mathrm{g} / \mathrm{dL}]$} & $4.6(0.4)$ \\
\hline AST & {$[\mathrm{U} / \mathrm{L}]$} & $19.0(6.0)$ \\
\hline ALT & {$[\mathrm{U} / \mathrm{L}]$} & $15.0(12.0)$ \\
\hline$\gamma$-GT & {$[\mathrm{U} / \mathrm{L}]$} & $17.0(12.8)$ \\
\hline $\mathrm{Cr}$ & {$[\mathrm{mg} / \mathrm{dL}]$} & $0.6(0.2)$ \\
\hline CRP & {$[\mathrm{mg} / \mathrm{dL}]$} & $0.03(0.05)$ \\
\hline BS & {$[\mathrm{mg} / \mathrm{dL}]$} & $90(13.0)$ \\
\hline $\mathrm{HbA} 1 \mathrm{c}$ & {$[\%]$} & $5.5(0.4)$ \\
\hline HDL-C & {$[\mathrm{mg} / \mathrm{dL}]$} & $65.0(19.0)$ \\
\hline LDL-C & {$[\mathrm{mg} / \mathrm{dL}]$} & $107(35.0)$ \\
\hline TG & {$[\mathrm{mg} / \mathrm{dL}]$} & $74.0(59.0)$ \\
\hline \multicolumn{3}{|c|}{ Adverse reactions $[\mathrm{n}(\%)]$} \\
\hline \multicolumn{3}{|c|}{ After 1st dose } \\
\hline Local & & $352(98.1)$ \\
\hline Systemic & & $215(59.9)$ \\
\hline \multicolumn{3}{|c|}{ After 2nd dose } \\
\hline Local & & $351(97.8)$ \\
\hline Systemic & & $324(90.3)$ \\
\hline \multicolumn{3}{|c|}{ Sleep duration (SD) $[\mathrm{n}(\%)]$} \\
\hline $\mathrm{SD} \leqq 2$ & & $1(0.3)$ \\
\hline 3 hours & 4 hours & $64(17.1)$ \\
\hline 5 hours & 7 hours & $297(79.4)$ \\
\hline 8 hours & 10 hours & $12(3.2)$ \\
\hline
\end{tabular}




\begin{tabular}{|c|c|}
\hline Good & $232(62.0)$ \\
\hline Disturbed & $142(38.0)$ \\
\hline The exercise hours $(\mathrm{EH})$ per day $[\mathrm{n}(\%)]$ & $271(72.5)$ \\
\hline $\mathrm{EH}<30$ minutes & $79(21.1)$ \\
\hline 30 minutes $\leqq \mathrm{EH}<1$ hour & $24(6.4)$ \\
\hline 1 hour $\leqq \mathrm{EH}$ & \\
\hline The numbers of outdoor exercises days per week [n (\%)] & $199(53.2)$ \\
\hline No & $175(46.8)$ \\
\hline More than once & \\
\hline The length of days for vaccination and antibody test, days & $8(1)$ \\
\hline 1st vaccination to 1st antibody test & $8(1)$ \\
\hline 2nd vaccination to 2nd antibody test & $22(3)$ \\
\hline 1st vaccination to 2nd vaccination & \\
\hline
\end{tabular}

1 


\section{Table 2 (on next page)}

Table 2. Comparison of parameters between LABG and non-LABG

Data are presented as the median (interquartile range) for continuous variables and the number (\%) for categorical variables. COPD, Chronic obstractive pulmonary disease; WBC, White blood cells; Hb, Hemoglobin; Hct, Hematocrit; PLT, Platelets; Alb, Albumin; AST, Asparate aminotransferase; ALT, alanine aminotransferase; $\gamma$-GT, $\gamma$-glutamyl transpeptidase; $\mathrm{Cr}$, Creatinine; CRP, C-reactive protein; BS, Blood sugar; HbAlc, Hemoglobin Alc; HDL-C, High density lipoprotein cholesterol; LDL-C, Low density lipoprotein cholesterol; TG, Triglyceride. 


\begin{tabular}{|c|c|c|c|}
\hline \multirow{3}{*}{$\begin{array}{l}\square \\
\\
\square\end{array}$} & \multicolumn{2}{|c|}{ Median (interquartile range) } & \multirow[b]{3}{*}{$p$ value } \\
\hline & LABG & non-LABG & \\
\hline & $(n=94)$ & $(n=280)$ & \\
\hline Age, years & $41.5(16.0)$ & $35(15.0)$ & $<0.001$ \\
\hline \multicolumn{3}{|l|}{$\operatorname{Sex}[\mathrm{n}(\%)]$} & \multirow{3}{*}{0.38} \\
\hline Male & $31(33.0)$ & $79(28.2)$ & \\
\hline Female & $63(67.0)$ & $201(71.8)$ & \\
\hline \multicolumn{4}{|l|}{ Body Mass Index: BMI [n (\%)] } \\
\hline $\mathrm{BMI}<18.5$ & $12(12.8)$ & $22(7.9)$ & \multirow{5}{*}{$<0.05$} \\
\hline $18.5 \leqq \mathrm{BMI}<25$ & $61(64.9)$ & $207(73.9)$ & \\
\hline $25 \leqq \mathrm{BMI}<30$ & $14(14.9)$ & $39(13.9)$ & \\
\hline $30 \leqq \mathrm{BMI}<35$ & $3(3.2)$ & $11(3.9)$ & \\
\hline $35 \leqq \mathrm{BMI}<40$ & $4(4.3)$ & $1(0.4)$ & \\
\hline \multicolumn{4}{|l|}{ Past Medical Histories [n (\%)] } \\
\hline Chronic lung disease (COPD) & $1(1.1)$ & $0(0)$ & \multirow{10}{*}{$<0.05$} \\
\hline Chronic lung disease (non-COPD) & $11(11.7)$ & $23(8.2)$ & \\
\hline Cardiac disease & $0(0.0)$ & $6(2.1)$ & \\
\hline Hypertension & $15(16.0)$ & $15(5.4)$ & \\
\hline Diabetes & $5(5.3)$ & $1(0.4)$ & \\
\hline Dyslipidemia & $9(9.6)$ & $7(2.5)$ & \\
\hline Liver disease & $2(2.1)$ & $4(1.4)$ & \\
\hline Chronic kidney disease & $0(0.0)$ & $4(1.4)$ & \\
\hline Autoimmune Disease & $4(4.3)$ & $3(1.1)$ & \\
\hline Cancer & $3(3.2)$ & $5(1.8)$ & \\
\hline \multicolumn{3}{|l|}{ Medication [n (\%)] } & \multirow{7}{*}{0.08} \\
\hline Antihypertensive drug & $13(13.8)$ & $15(5.4)$ & \\
\hline Antidiabetic drug & $5(5.3)$ & $0(0.0)$ & \\
\hline Antilipid drug & $8(8.5)$ & $5(1.8)$ & \\
\hline Anticoagulant / Antiplatelet drug & $1(1.1)$ & $1(0.4)$ & \\
\hline Immunosuppresive drug & $1(1.1)$ & $2(0.7)$ & \\
\hline Immunoglobulin preparations & $4(4.3)$ & $0(0.0)$ & \\
\hline
\end{tabular}




\begin{tabular}{|c|c|c|c|c|}
\hline \multicolumn{2}{|c|}{ Smoking $[\mathrm{n}(\%)]$} & & & \multirow{3}{*}{0.74} \\
\hline \multicolumn{2}{|c|}{ Current smoking [n (\%)] } & $20(21.3)$ & $50(17.9)$ & \\
\hline \multicolumn{2}{|c|}{ Past smoking [n (\%)] } & $20(21.3)$ & $44(15.7)$ & \\
\hline \multicolumn{2}{|c|}{ Drinking Alcohol [n (\%)] } & $62(66.0)$ & $167(59.6)$ & 0.28 \\
\hline \multicolumn{5}{|c|}{ Laboratory test } \\
\hline WBC & {$\left[\times 10^{3} / \mu \mathrm{L}\right]$} & $6.4(2.4)$ & $6.3(1.9)$ & 0.94 \\
\hline $\mathrm{Hb}$ & {$[\mathrm{g} / \mathrm{dL}]$} & $14.1(1.4)$ & $13.8(1.9)$ & 0.37 \\
\hline Hct & {$[\%]$} & $40.9(4.5)$ & $40.0(4.3)$ & 0.44 \\
\hline PLT & {$\left[\times 10^{4} / \mu \mathrm{L}\right]$} & $25.2(6.8)$ & $25.2(7.3)$ & 0.99 \\
\hline & {$[\mathrm{g} / \mathrm{dL}]$} & $4.6(0.4)$ & $4.6(0.4)$ & 0.06 \\
\hline AST & {$[\mathrm{U} / \mathrm{L}]$} & $19.0(7.5)$ & $19.0(5.0)$ & 0.20 \\
\hline ALT & {$[\mathrm{U} / \mathrm{L}]$} & $17.0(11.8)$ & $15.0(11.0)$ & 0.05 \\
\hline$\gamma$-GT & {$[\mathrm{U} / \mathrm{L}]$} & $19.0(16.0)$ & $16.0(11.3)$ & $<0.001$ \\
\hline $\mathrm{Cr}$ & {$[\mathrm{mg} / \mathrm{dL}]$} & $0.66(0.2)$ & $0.63(0.2)$ & 0.67 \\
\hline CRP & {$[\mathrm{mg} / \mathrm{dL}]$} & $0.03(0.04)$ & $0.03(0.05)$ & 0.29 \\
\hline BS & {$[\mathrm{mg} / \mathrm{dL}]$} & $91.0(17.5)$ & $90.0(12.0)$ & 0.05 \\
\hline $\mathrm{HbAlc}$ & {$[\%]$} & $5.6(0.5)$ & $5.5(0.4)$ & $<0.01$ \\
\hline HDL-C & {$[\mathrm{mg} / \mathrm{dL}]$} & $65.0(20.0)$ & $65.0(19.0)$ & 0.90 \\
\hline LDL-C & {$[\mathrm{mg} / \mathrm{dL}]$} & $107.0(33.8)$ & $107.0(36.0)$ & 0.80 \\
\hline TG & {$[\mathrm{mg} / \mathrm{dL}]$} & $75.0(65.5)$ & $73.0(54.0)$ & 0.67 \\
\hline \multicolumn{4}{|c|}{ Adverse reactions [n (\%)] } & \multirow{7}{*}{0.71} \\
\hline \multicolumn{4}{|c|}{ After 1st dose } & \\
\hline Local & & $86(96.6)$ & $266(98.5)$ & \\
\hline System & & $45(50.6)$ & $170(63.0)$ & \\
\hline \multicolumn{4}{|c|}{ After 2nd dose } & \\
\hline Local & & $88(98.9)$ & $263(97.4)$ & \\
\hline System & & $78(87.6)$ & $246(91.1)$ & \\
\hline \multicolumn{5}{|c|}{ Sleep duration (SD) [n (\%)] } \\
\hline $\mathrm{SD} \leqq 2$ & & $1(1.1)$ & $0(0)$ & \multirow{3}{*}{0.33} \\
\hline 3 hours & $<4$ hours & $16(17.0)$ & $48(17.1)$ & \\
\hline 5 hours & $<7$ hours & $75(79.8)$ & $222(79.3)$ & \\
\hline
\end{tabular}




\begin{tabular}{|c|c|c|c|}
\hline 8 hours $\leqq \mathrm{SD}<10$ hours & $2(2.1)$ & $10(3.5)$ & \\
\hline \multicolumn{3}{|l|}{ The quality of sleep $[\mathrm{n}(\%)]$} & \multirow{3}{*}{0.75} \\
\hline Good & $57(60.6)$ & $175(62.5)$ & \\
\hline Disturbed & $37(39.4)$ & $105(37.5)$ & \\
\hline \multicolumn{4}{|l|}{ The exercise hours $(\mathrm{EH})$ per day $[\mathrm{n}(\%)]$} \\
\hline $\mathrm{EH}<30$ minutes & $66(70.2)$ & $205(73.2)$ & \multirow{3}{*}{0.82} \\
\hline 30 minutes $\leqq \mathrm{EH}<1$ hour & $22(23.4)$ & $57(20.4)$ & \\
\hline 1 hour $\leqq \mathrm{EH}$ & $6(6.4)$ & $18(6.4)$ & \\
\hline \multicolumn{3}{|c|}{ The numbers of outdoor exercises days per week [n (\%)] } & \multirow{3}{*}{$<0.001$} \\
\hline No & $64(68.1)$ & $135(48.2)$ & \\
\hline More than once & $30(31.9)$ & $145(51.8)$ & \\
\hline \multicolumn{4}{|c|}{ The length of days from vaccination to antibody test, days } \\
\hline 1 st vaccination to 1 st antibody test & $8(1)$ & $8(1)$ & 0.90 \\
\hline 2 nd vaccination to 2 nd antibody test & $8(0)$ & $8(1)$ & $<0.05$ \\
\hline 1 st vaccination to 2 nd vaccination & $22(2)$ & $22(3)$ & $<0.05$ \\
\hline
\end{tabular}




\section{Table 3 (on next page)}

Table 3. Univariate and multivariate logistic regression analysis of factors associated with low-antibody titer after vaccination.

COPD, Chronic obstractive pulmonary disease; WBC, White blood cells; Hb, Hemoglobin; Hct, Hematocrit; PLT, Platelets; Alb, Albumin; AST, Asparate aminotransferase; ALT, alanine aminotransferase; $\mathrm{\gamma}$-GT, $\mathrm{\gamma}$-glutamyl transpeptidase; $\mathrm{Cr}$, Creatinine; CRP, C-reactive protein; BS, Blood sugar; HbAlc, Hemoglobin Alc; HDL-C, High density lipoprotein cholesterol; LDL-C, Low density lipoprotein cholesterol; TG, Triglyceride. 


\begin{tabular}{|c|c|c|c|c|}
\hline \multirow{2}{*}{ Predictor } & \multicolumn{2}{|l|}{ Univariate } & \multicolumn{2}{|c|}{ Multivariate } \\
\hline & Odds ratio $(95 \% \mathrm{CI})$ & $p$ value & Odds ratio $(95 \% \mathrm{CI})$ & $p$ value \\
\hline Age $\geqq 60$ years $(\mathrm{vs}<60$ years $)$ & $4.70(1.30-17.05)$ & $<0.05$ & $4.99(1.25-19.85)$ & $<0.05$ \\
\hline \multicolumn{5}{|l|}{ Sex } \\
\hline Male (vs Female) & $1.25(0.76-2.07)$ & 0.38 & & \\
\hline \multicolumn{5}{|l|}{ Body Mass Index: BMI } \\
\hline $\mathrm{BMI} \geqq 30(\mathrm{vs}<30)$ & $1.80(0.69-4.70)$ & 0.23 & & \\
\hline \multicolumn{5}{|l|}{ Past Medical Histories } \\
\hline Hypertension (vs no Hypertension) & $3.35(1.57-7.16)$ & $<0.01$ & $2.58(1.11-6.02)$ & $<0.05$ \\
\hline Current smoking (vs no Current smoking) & $1.24(0.70-2.22)$ & 0.46 & & \\
\hline \multicolumn{5}{|l|}{ Laboratory test } \\
\hline $\mathrm{HbA} 1 \mathrm{c} \geqq 6.5 \%(\mathrm{vs}<6.5)$ & $14.72(3.12-69.43)$ & $<0.001$ & $10.99(2.07-58.20)$ & $<0.01$ \\
\hline \multicolumn{5}{|l|}{ Sleep duration (SD) } \\
\hline $\mathrm{SD}<4$ hours (vs $\geqq 4$ hours) & $1.07(0.58-1.96)$ & 0.83 & & \\
\hline \multicolumn{5}{|l|}{ The exercise hours $(\mathrm{EH})$ per day } \\
\hline $\mathrm{EH}<30$ minutes $(\mathrm{vs} \geqq 30$ minutes $)$ & $0.86(0.51-1.44)$ & 0.57 & & \\
\hline \multicolumn{5}{|l|}{ The numbers of outdoor exercises days per week } \\
\hline No (vs more than once per week) & $2.29(1.40-3.75)$ & $<0.001$ & $2.39(1.41-4.03)$ & $<0.01$ \\
\hline The length of days from vaccination to antibody test, days & & & & \\
\hline 1st vaccination to 2 nd vaccination $>25$ days (vs $\leqq 25$ days) & $0.49(0.27-0.88)$ & $<0.05$ & $0.47(0.25-0.89)$ & $<0.05$ \\
\hline
\end{tabular}

2 